\title{
El pensamiento económico de Adolfo Meisel Roca: los desequilibrios económicos y sociales regionales en Colombia*
}

\author{
The economic thinking of Adolfo Meisel Roca: \\ Regional economic and social imbalances in Colombia
}

\begin{abstract}
Carlos Delgado Gómez
Profesor Escuela de Economía, Integrante del Grupo de Investigación SOECOL de la Escuela de Economía, Universidad Pedagógica y Tecnológica de Colombia, Colombia

https://orcid.org/0000-0002-7963-9792 carlos.delgado@uptc.edu.co
\end{abstract}

Luis Miguel Meza Espinosa

Profesor Escuela de Economía, Integrante del Grupo de Investigación SOECOL de la Escuela de Economía, Universidad Pedagógica y Tecnológica de Colombia, Colombia https://orcid.org/0000-0001-9865-2186 luis.meza@uptc.edu.co

Fecha de recepción: 119 de septiembre de 2017 Fecha de aceptación: 24 de noviembre de 2017

Sugerencia de citación: Delgado Gómez, C. y Meza Espinosa, L.M. (2018). El pensamiento económico de Adolfo Meisel Roca: los desequilibrios económicos y sociales regionales en Colombia. tiempo\&economía, 5(1), 123-140, doi: http://dx.doi.org/10.21789/24222704.1303

* Ensayo basado en una entrevista con Adolfo Meisel Roca, realizada en septiembre de 2014 en la Universidad Pedagógica y Tecnológica de Colombia, Tunja, y la consulta de sus publicaciones. Los autores agradecen a Adolfo Meisel las correcciones y sugerencias a un primer texto del material de la entrevista. 


\title{
RESUMEN
}

Uno de los campos menos desarrollados en la historiografía económica de América Latina y aún menos en Colombia es el de los ensayos biográficos. Este tipo de ensayos iluminan las circunstancias en las que se forjaron los trabajos más influyentes de ciertos autores, las influencias que fueron permeando su labor y las motivaciones intelectuales y políticas que impulsaron su obra. En este ensayo nos hemos basado en una extensa entrevista concedida por Adolfo Meisel Roca, quien es uno de los historiadores más influyentes de Colombia en la actualidad, no sólo por haber contribuido a iluminar muchos de los rincones poco explorados de la historia económica, sino por su liderazgo y participación en estudios sociales y económicos de las regiones olvidadas del país.

Palabras clave: historia económica, desequilibrios regionales, proceso económico, historia regional.

Códigos JEL: B2, B3, B31, N01, O18, R5

\begin{abstract}
One of the least developed fields in the economic historiography of Latin America and even less of Colombia is the field of biographical essays. This type of essays highlight the circumstances in which the most influent works of certain authors were conceived, the influences that permeated them and the intellectual and political motivations that propelled their ouvre. We have based this essay on an extensive interview conceded by Adolfo Meisel Roca, who is currently one of the most influent historians in Colombia, not only for having contributed to illuminate many of the least explored corners of economic history, but for his leadership and participation in social and economic studies in the forgotten regions of the country.
\end{abstract}

Keywords: economic history, regional imbalances, economic process, regional history.

JEL Codes: B2, B3, B31, N01, O18, R5 


\section{Introducción}

Para encarar al personaje: Adolfo Meisel, lo situamos en su entorno global para discernir sus ideas, valores, normas, modos de producción intelectual, instintos y sentimientos, recurriendo a un enfoque más sintético que analítico que evade la compartimentación del autor en escuelas, tendencias o categorías específicas. Esto para establecer la formación académica y familiar de un autor que pudo desarrollar a fondo sus capacidades en un medio social estático que de pronto no era el más propicio para lograrlo.

Esta apretada perspectiva figuracional inicia con los orígenes familiares de Adolfo Meisel que pueden ayudar a evidenciar procesos germinativos en maneras de pensar de un autor. Los estudios y los momentos procesuales de elección, el desempeño académico y profesional, las influencias académicas e intelectuales y los resultados de acciones específicas denotan particularidades que sólo tienen sentido, en un proceso de formación de un economista, cuando se destacan íntegramente.

Este enfoque pretende desarrollar desde una perspectiva social y académica, la psicogénesis y sociogénesis inmersa en una metodología de apreciación de procesos de formación de economistas en Colombia (Elías, 1994).

Se destacan los procesos llevados a cabo por Adolfo Meisel en relación con la creación desde el Banco de la República en Cartagena, de grupos de investigación con apoyos técnico institucionales, de organización social, académica e investigativa y financieros para llevar a cabo una serie de estudios que - de una u otra manera- destacan los desequilibrios económicos y sociales en Colombia desde la perspectiva de una historia económica regional.

\section{Enfoque teórico}

Escribir sobre las distintas influencias personales, académicas e intelectuales de un autor que significan el origen de una manera de pensar en economía, implica destacar que "la tendencia prevaleciente hacia el pensamiento dicotómico y dualista" (Elías y Dunning, 2016, p. 43) limita tanto la comprensión de los planteamientos, como"la comprensión de los seres humanos y de las sociedades que forman" (ibíd.).

En consecuencia, esclarecer las relaciones entre maneras de pensar y el conjunto de caracteres propios de un grupo social y académico, en el cual se encuentra inmerso un autor como Adolfo Meisel Roca, requiere estudiar la persona en sentido integral, y "no sólo aspectos particulares de sus vidas tales como las ideas, los valores y las normas, los modos de producción intelectual, los instintos y sentimientos y su sublimación" (Elías y Dunning, 2016, p. 43).

Este tipo de acercamiento al pensamiento de un autor puede ser "una contribución al desarrollo de un método para abordar el nivel humano-social de la integración entre el autor y su formación intelectual, académica y familiar que fundamenta una manera de pensar con un aparato conceptual más a tono con la naturaleza dinámica y relacional de los seres humanos y de sus sociedades" (Elías y Dunning, 2016, p. 46).

Pero es una manera de pensar que es "relativamente autónoma y cuenta con unas propiedades emergentes que son únicas, como lenguajes, códigos morales, relaciones de 
parentesco, matrimonio, crisis, que se caracterizan por regularidades propias que no pueden explicarse reductivamente, es decir, con métodos, conceptos y modelos tomados del estudio de los fenómenos que acontecen" (ibíd.).

Por tanto, se tienen en cuenta "los conceptos conexos 'figuraciones' $y$ 'seres humanos abiertos', en donde el primero se refiere a un tejido de personas interdependientes, ligadas entre sí en varios niveles y de varias maneras. El segundo, al carácter abierto, de proceso, inherentemente dirigido al otro que tienen los individuos que forman tales figuraciones" (ibíd.).

Un pensador como Adolfo Meisel no es un caso particular, como si existiera por sí solo y se desarrollara únicamente de acuerdo con su propia dinámica endógena (ibíd., p. 51), antes bien, denota una serie de interdependencias que tienen que ver con los lugares de origen, la familia, la formación y los procesos educativos, los momentos de elección, los grupos sociales y las instituciones, entre otras.

\section{Los orígenes familiares}

En la fase formativa familiar, Adolfo Meisel hace parte de las cualidades pedagógicas ${ }^{1}$ de un grupo de maestros de Escuelas Normales, entre los cuales el Profesor Carlos Meisel ${ }^{2}$ quién hizo parte de la Primera Misión Pedagógica Alemana, ${ }^{3}$ llega a Santa Marta en 1871, iniciando una descendencia que se radica generación tras generación entre Barranquilla, Ocaña y nuevamente Barranquilla y finalmente Cartagena.

El profesor Carlos Meisel se radica en Barranquilla a fines de la década de 1870. Algunos descendientes del profesor Carlos Meisel, es decir, la segunda generación viajaron por el Río Magdalena y subieron hasta Ocaña en los primeros años de la década de 1920. Luego los abuelos paternos de Adolfo Meisel Roca se establecen en Barranquilla en donde nacen sus padres. La abuela materna era hija de José Félix Fuenmayor Reyes, médico inmigrante venezolano y Ana Arrázola Romero de la ciudad de Sincelejo. Los abuelos maternos, que llegaron en la década de 1940, provenientes de Ocaña, también vivieron en Barranquilla.

Los padres de Adolfo Meisel se radican en Cartagena en la década de 1950, por lo que Meisel hace sus estudios de pri maria y Bachillerato en esta misma ciudad. Por esta razón, suele afirmar que: "Los barranquilleros lo califican como cartagenero y los cartageneros como barranquillero".

Cuando fue nombrado en la Junta Directiva del Banco de la República en Bogotá, en algunos periódicos de Barranquilla escribieron que su origen era barranquillero y los cartageneros

1 "Los maestros alemanes se comprometen a fundar y dirigir, en la capital del respectivo Estado una Escuela Normal y una elemental modelo a ella adjunta; a dar en la primera las enseñanzas que se dan en las Escuelas Normales de Prusia y a indicar al maestro o maestros que dirijan la segunda, el método pestalozziano, como se practica en las escuelas elementales prusianas" (Bohorquez, 1956, p. 361).

2 Bohorquez (1956, p. 361) dice:“El Cónsul colombiano en Berlín celebra contrato con los siguientes profesores alemanes: Gotthold Weiss para el Estado de Antioquia; Julio Wallner para el de Bolívar; Augusto Pankou para el de Cauca; Carlos Meisel para el Magdalena"; siguen cinco profesores para los Estados Soberanos de Panamá, Cundinamarca, Tolima, Boyacá y Santander.

3 Periodos de las misiones pedagógicas alemanas en Colombia: 1872-1878, 1924-1935 y 1965-1978. Para mayor información sobre los objetivos de la primera misión alemana, ver Muller (s.f.). 
se quejaron. Le tocó precisar que nació en Barranquilla y estudió desde segundo elemental hasta finalizar el bachillerato en Cartagena. Esta es la razón por la cual tiene muchos más familiares en Barranquilla que en Cartagena. Además, visitaba frecuentemente a sus abuelos en Barranquilla.

Para Meisel, Barranquilla es una ciudad abierta, y no tiene nada que ver con la tradición colonial de Cartagena, en donde, la presencia de inmigrantes no es tan fuerte, más bien escasa. De manera que no se siente un foráneo en ninguna de las dos ciudades y expresa un inmenso cariño por ambas.

Su padre era un lector asiduo de Mecánica Popular y muy hábil para actividades como la mecánica y la electrónica; un radioaficionado que sabía lo práctico de la electrónica y que deseaba compartir con su hijo de esta pasión, pero a este no le llamaba mucho la atención este tipo de actividades. Como ayudante de su padre desarrolló algunas tareas, pero las detestaba porque eran más prácticas que intelectuales.

El deporte y la lectura fueron actividades de su interés, pero su padre le decía que no leyera tanto. Su señora madre se preocupaba y con razón, porque cuando llegaba su padre en la madrugada, le recomendaba detener la lectura porque el siguiente día tenía clases, y debía estar listo a las seis de la mañana.

Cuando tenía siete años su señora madre adquirió una enciclopedia coleccionable por fascículos semanales, porque observaba la pasión del hijo por la lectura, aunque ella no era una lectora consumada. Cada semana estaba atento a la llegada de cada fascículo para leer y completar cada tomo. Recuerda las imágenes de la enciclopedia, entre ellas la de la Batalla de las Termópilas en Paya, Provincia de Tunja, que no ha borrado de su mente.

\section{Los estudios}

Una empresa norteamericana contratada para construir la Refinería de Cartagena, construyó y regentó un colegio para los hijos de sus empleados norteamericanos y estudiantes locales. Meisel adelantó sus estudios de secundaria en este colegio, el cual no contaba con aprobación de las autoridades educativas de Colombia y de Estados Unidos.

En ese colegio había una interesante biblioteca en inglés, la cual consideraban importante para la formación de los estudiantes. Adolfo demostraba interés por la literatura, la historia y las ciencias sociales. Las materias que menos le gustaban eran matemáticas y ortografía.

Recuerda que la primera influencia intelectual que afianzó su interés por la historia provino de un profesor norteamericano, James Park, quién contaba con una maestría en Historia de América Latina. Ese profesor luego regresó a Estados Unidos y escribió su tesis doctoral sobre Rafael Núñez y el regionalismo político en Colombia en el siglo XIX. ${ }^{4}$

Otra influencia intelectual la recibió de un profesor norteamericano de literatura inglesa, Peter Schram, quién avivó su entusiasmo por la lectura de las obras de Shakespeare.

4 Esta fue publicada como Rafael Núñez and the Politics of Colombian Regionalism 1863-1886. Baton Rouge: Louisiana State University Press, 1985. 
Si bien la influencia de la literatura inglesa fue intensa, también le atraía la historia. Una de las características fundamentales de la educación anglosajona es la escritura que se adquiere con mucha práctica. Gracias a ello, aprendió a escribir ensayos muy temprano, tareas que son un reto mayor porque se requiere una estructura lógica para poder expresar las ideas de manera coherente. No era una educación de tipo escolástico o formalista, como la que se desarrollaba en ese momento en otros colegios de Cartagena y en el sistema colombiano en general. Se fomentaba la investigación y la independencia para estudiar diferentes temas.

Tal vez por esto, en la actualidad es un crítico de los cursos de metodología de la investigación, porque son predominantemente escolásticos dictados por profesores que poco investigan y nunca publican. La metodología de la investigación debe ser una intensa práctica tutorial, basada más que todo en el sentido común y en el afán de hacerse entender por sus lectores.

Como Director del periódico estudiantil editó varios números con sus compañeros. También en el colegio escribió algunos ensayos en los que recurrió a la obra de Jaime Jaramillo Uribe sobre historia social y económica de Colombia (Jaramillo, 1964).

En quinto de bachillerato tuvo la oportunidad de hacer un intercambio en Mesa, Arizona, Estados Unidos. Allí había muchas más opciones académicas que en el colegio de Cartagena y podía elegir entre una gran cantidad de materias electivas. Por ejemplo, se decidió por un curso de escritura creativa y escribió en inglés un cuento que fue publicado en la revista de literatura del colegio. Recuerda que era una narración sobre una corrida de toros, porque había asistido alguna vez en Cartagena a la antigua plaza de la Serrezuela cuando tenía nueve años y quedó impresionado por el espectáculo.

\section{La elección de estudios superiores}

Empezando el segundo semestre de 1972 obtuvo su grado de la secundaria y viajó a Bogotá para ingresar a la Universidad de Los Andes en la carrera de Derecho.

En la Universidad de Los Andes uno de los profesores de Historia Económica de Colombia, se refería a "los costeños" de una manera muy burlona y desagradable. Era claro que en Bogotá no se conocía la historia económica y social de la Costa Caribe: otro profesor decía que no había historia regional de la Costa Caribe porque los costeños no guardaban sus archivos por razones culturales. Hoy en día sabemos que algunos de los mejores archivos empresariales del país están en el caribe colombiano, como por ejemplo, el archivo de la familia Castillo de Cartagena.

En la época de Los Andes lo atrajo como método de análisis el materialismo histórico. Sin embargo, se alejó emocionalmente de la izquierda al conocer como era su actividad política. Estuvo cerca intelectualmente del materialismo histórico a pesar de su desencanto con la práctica política de la izquierda colombiana.

Fue solo cuando adelantó estudios de maestría y doctorado en sociología que leyó a autores que lo llevaron a entender las enormes limitaciones del materialismo histórico. Esto ocurrió con el estudio de Max Weber (1864-1920), Albert Hirschman (1915-2012), Isaiah Berlin (19091997), Joseph A. Schumpeter (1883-1950), entre otros autores de tendencia liberal clásica. 
El inicio de sus estudios universitarios no fue en Economía, porque para la elección contaba con dos opciones: Economía o Derecho. No tenía realmente claro qué era economía y conocía un poco más a abogados destacados. Por eso entró a Derecho, pero casi inmediatamente se dio cuenta que eso no le atraía. Los compañeros le sugirieron en consecuencia cambiar de carrera, pero sólo tomó la decisión hasta terminar el semestre, para estar más seguro. Para Meisel la experiencia en Derecho fue decepcionante y lo vivió desde una perspectiva cínica, como un juego argumentativo. Sin embargo, obtuvo muy buenas notas.

Finalmente se decidió por los estudios de Economía, en donde los compañeros de estudio eran más cercanos en intereses y congeniaba más con ellos y con los profesores. Además, encontró más posibilidades para hacer investigación académica de su interés.

La ciencia como tal, le interesaba desde el colegio, por lo que consideró estudiar medicina, debido a que le atraía la genética, y porque había sido un buen estudiante en biología, pero se desanimó un poco, porque su mejor amigo quería ser un médico y era un apasionado por la parte clínica de la medicina y en las vacaciones asistía al hospital Santa Clara a hacer prácticas. Ese ambiente que no era de su gusto; consideraba que si la medicina sólo era la cirugía no era de su interés. Si no hubiera desarrollado esa percepción tal vez negativa de la medicina, de pronto hubiera terminado estudios como médico.

La llegada a la Universidad de los Andes, coincidió con una huelga y como primíparo, no entendía con certeza lo que estaba pasando, sólo comprendió algo cuando la Universidad estuvo cerrada por un mes. Era la primera vez que sucedía esto. Como consecuencia regresa a Cartagena durante varias semanas.

Reabierta la universidad, las lecturas se realizaron sobretodo en grupos de estudio, donde leyeron autores como Marta Harnecker (2007). Los grupos de estudio persistieron durante casi toda la carrera de economía, pero también participó en grupos de estudio con antropólogos. En uno de estos grupos estaba Vera Grave, estudiante de la cual casi nadie se imaginaba en los compromisos políticos en que andaba, Meisel recuerda que ella era disciplinada y callada.

Las lecturas de Juan Rulfo, Carlos Fuentes y otros autores del boom latinoamericano fueron un gran descubrimiento de la mano de María Teresa Cristina ${ }^{5}$ y Gretel Wernher. ${ }^{6}$ Si bien había leído abundante literatura en el bachillerato, sus lecturas en esa época fueron sobretodo de poetas ingleses y norteamericanos. Recuerda de esa época del colegio la lectura de Werther de Goethe. Años después volvió a leerlo y no le gustó. También leyó en el colegio a Sartre y mucho teatro, pero fue solo en Bogotá en donde por primera vez fue a teatro. Desde entonces no lee teatro pero si le encanta ir a teatro y cuando viaja a Estados Unidos y Europa siempre trata de asistir a alguna función.

Si bien en el colegio se entusiasmó por la lectura de Sartre, con el paso del tiempo muchas de sus obras literarias dejaron de cautivarlo. En contraste, en la década de 1980 descubrió a Raymond Aron, bastante crítico de Sartre, y ahora siente mayor afinidad con Aron que con otros intelectuales franceses del siglo XX.

5 Investigadora y profesora de origen italiano.

6 Autora con Jorge Páramo del libro Micenas y Homero. Bogotá: Instituto Caro y Cuervo, 1995.

tiempo\&economía

Vol. 5 N.॰ 1 - Enero - Junio de 2018

p. 129

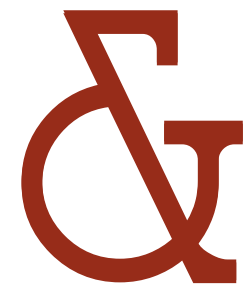


En la Universidad de Los Andes le correspondió como profesor consejero en toda la carrera Jorge García quién fue tal vez el primer economista colombiano con PhD en economía de la Universidad de Chicago. Era muy riguroso como economista, y más que un buen matemático, manejaba la lógica económica. La Universidad de Chicago es rigurosa en los razonamientos económicos, lo que la define, y considera que por esta razón han tenido muchos premios nobel en economía, porque son rigurosos con la lógica económica: un tipo de razonamiento con una fundamentación en microeconomía muy exigente.

Tomó los cursos de introducción a la economía y un curso de lectura de microeconomía. Fue una formación microeconómica exigente. Por eso considera que tuvo una formación económica inmejorable en el pregrado de la Universidad de Los Andes.

Luego tomó cursos sobre aspectos monetarios con otro profesor que también había estudiado en Chicago. A pesar de los prejuicios que tenía contra la teoría monetaria, porque consideraba que la problemática de la moneda era un epifenómeno, resultó que fue una de las materias que más disfrutó en el pregrado. Y en el doctorado en economía, tomó como área de especialización la teoría monetaria. Considera que le ha servido tanto, para la investigación histórica, como para la actividad profesional en la cual finalmente terminó, la banca central.

Cuando ingresó al Banco de la República investigó sobre la historia monetaria de Colombia y la historia del Banco de la República. Esos estudios le han servido ahora que hace parte de la Junta Directiva del Banco de la República. Considera que nunca se sabe para qué le pueden servir a una persona los temas aprendidos durante la vida académica, pero está convencido que la historia atrae su atención y de hecho cuando estudió el pregrado en la Universidad de Los Andes, cursó muchas electivas de Historia. Tomó dos cursos con Margarita González (1942-2008), otra influencia intelectual. Ella tenía como método, la lectura de los libros de historia tradicional, aunque en esa época no estaba de moda ese tipo de lecturas, pues consideraba que había que conocer muy bien la Historiografía nacional. A menudo se encuentra uno con economistas colombianos con excelente formación en matemáticas y teoría económica pero con un desconocimiento de nuestro pasado. Eso le parece lamentable.

También recuerda la influencia intelectual del profesor Jaime Jaramillo Uribe, de quién fue asistente de investigación durante un año. Finalmente Jaime Jaramillo dirigió la que iba a ser su tesis de pregrado, pero no la terminó porque decidió graduarse con el programa coterminal, que consistía en continuar con estudios de maestría desde el pregrado.

\section{Temas de investigación}

La investigación para la tesis de pregrado en economía fue sobre la formación de las haciendas en la Costa Caribe en el periodo colonial. La desarrolló en el Archivo General de la Nación y la publicó como un artículo antes de viajar a Illinois a estudiar el doctorado en economía. Fue su primer artículo publicado "Esclavitud, Mestizaje y Haciendas en la provincia de Cartagena, 1533-1851",7 un estudio de evolución de las relaciones de producción en las zonas rurales de la antigua provincia de Cartagena durante el periodo colonial y hasta 1851. La antigua provincia de Cartagena ocupaba el territorio que hoy comprenden los departamentos de

7 Desarrollo y Sociedad, 4, julio de 1980, CEDE. Bogotá: Uniandes. 
Atlántico, Bolívar, Sucre y Córdoba. Analizó la evolución de las haciendas esclavistas, haciendo uso de la demografía histórica para descubrir sus características y las bases de su evolución. El método de análisis fue el materialismo histórico.

La motivación para haber estudiado la formación de las haciendas en la Costa Caribe en el periodo colonial era el deseo de comprender el problema agrario en Colombia, que en los años setenta fue un tema álgido. Fue la época del apogeo en la costa de la Asociación Nacional de Usuarios Campesinos (ANUC) línea Sincelejo. Siendo estudiante de economía en el año 1975 tuvo contacto con dirigentes de ANUC en Cartagena, como por ejemplo Richard May, un líder carismático que comisionó a varios estudiantes universitarios como maestros de Historia Agraria de campesinos integrantes de la ANUC. Esa experiencia lo hizo ver lo poco que se sabía sobre la historia agraria de la Costa, y por eso decidió hacer su investigación en ese tema.

Durante los estudios de maestría en Los Andes tuvo un profesor en macroeconomía, Fernando Montes, que luego ocupó el cargo de Subgerente de Estudios Económicos del Banco de la República. Cuando regresó del doctorado en economía, Montes, que recordaba su interés por la historia, lo invitó para desarrollar un proyecto de investigación sobre la historia del Banco de la República.

Su decisión para irse a cursar un doctorado en economía en la Universidad de Illinois fue fruto de un error burocrático. Meisel había aplicado a varias universidades en Estados Unidos para empezar en agosto de 1980. Sin embargo, la Universidad de Illinois le envió a fines de noviembre de 1979 la aceptación para empezar el doctorado en economía en enero de 1980. Por eso decidió irse enseguida a estudiar en Illinois. Para financiarse vendió un Renault 4 que había comprado a crédito, y con los ingresos pagó la deuda, y el saldo de tres mil dólares, le permitió viajar y pagar la matrícula del primer semestre, la vivienda y las tres comidas en la cafetería de la Universidad.

Sin embargo, durante la primera semana de clases salió una convocatoria para una beca de matrícula que alguien no había tomado. Aplicó, se la ganó y le devolvieron el dinero que había pagado de matrícula. De allí en adelante siempre tuvo beca de matrícula y además, desde el segundo semestre de 1980 siempre trabajó en la universidad como instructor asistente o como asistente de investigación.

La situación difícil se presentaba en las vacaciones porque no había ingresos como instructor ya que los cursos de vacaciones sólo los asignaban a los mejores instructores, que usualmente eran de origen norteamericano.

Recuerda la intensidad de los estudios de doctorado, particularmente en los dos primeros años, es decir, una maestría en economía que obtuvo en 1981 y luego el doctorado del que se graduó en 1984.

En el curso de Historia Económica descubrió la nueva historia económica leyendo a Robert William Fogel (1926-2013) premio nobel de Economía en 1993 y gestor de la historia económica moderna. Leyó su libro Time on the cross: The economics of American Slavery (1974) e hizo un trabajo de análisis sobre el contenido de esa obra. Fogel ha sido uno de los autores de mayor influencia intelectual en su vida como investigador. 
Considera que Robert Fogel es el historiador económico más importante del siglo XX, aunque en Colombia es más popular Douglass North (1920-2015). Fogel y North compartieron el premio Nobel de Economía, por los aportes a la investigación en historia económica con aplicaciones de teorías y métodos para explicar los cambios institucionales y económicos.

Fogel aportó a la historia económica una estimación econométrica del impacto de los ferrocarriles sobre el desarrollo económico de Estados Unidos en el siglo XIX (Fogel, 1960; 1964). Allí concluyó que ese impacto había sido limitado, aunque hasta ese momento se pensaba que sin ferrocarriles no se hubiera dado la expansión de la economía norteamericana en el siglo XIX.

Fogel calculó qué hubiera pasado si no hubieran sido construidos los ferrocarriles. En ese caso - decía él- se hubieran construido vías, canales fluviales, más caminos y se hubiera usado carretas. El ahorro con los ferrocarriles lo estimó en 3\% al 4\% del PIB, es decir, no fue imprescindible para el proceso de desarrollo en Estados Unidos.

El segundo gran trabajo de Fogel es una reinterpretación de la esclavitud en el sur de los Estados Unidos, porque la interpretación tradicional se planteaba desde la perspectiva de un modo de producción anticuado y poco productivo, que se mantenía en el sur de los Estados Unidos por razones ideológicas y no económicas. Fogel demostró que la esclavitud era tan productiva como la agricultura libre del norte de Estados Unidos y los esclavos vivían relativamente bien remunerados. Este argumento generó controversias y críticas, y varios libros atacaron los planteamientos de Fogel.

Los historiadores que criticaron a Fogel por su estudio de la esclavitud argumentaron que el nivel de vida de los esclavos no era bueno. La evidencia era contradictoria. Fogel argumentó con el uso de datos de estatura que la nutrición de los esclavos era buena. De ese interés por la estatura surgió uno de los campos hoy en día más vitales en la historiografía económica en el mundo: la antropometría. Ese es uno de los aportes más relevantes de Fogel a los estudios de historia económica.

Los trabajos de Fogel en este campo le llamaron la atención y Meisel empezó a investigar el tema. Tuvo la suerte de que Colombia es de los pocos países que registra la estatura en la cédula de ciudadanía y obtuvo esa base de datos en la Registraduría Nacional del Estado Civil, de alrededor de nueve millones de cédulas para los nacidos desde 1910 hasta 1984.

Esta base de datos le permitió investigar la antropometría en Colombia: "Es un estudio de la evolución de la estatura promedio de los colombianos de 1910 a 2002. La evidencia antropométrica revela un sostenido mejoramiento en los estándares de vida biológicos en ese periodo. Utiliza una base de datos con más de 9 millones de observaciones de las Cédulas de ciudadanía de hombres y mujeres. Demuestra un incremento significativo en la estatura de los nacidos entre 1910 y 1984 . El promedio de estatura aumentó en 9 centímetros para las mujeres y 8 para los hombres. La dispersión de la estatura, medida a través del coeficiente de variación, cayó para el periodo, mostrando un proceso de convergencia en los estándares de calidad de vida biológica" (Meisel y Vega, 2004).

Lo interesante de este trabajo es que ha habido en Colombia un aumento de la estatura en todas las regiones, con convergencia, lo que demuestra una mejoría en la calidad de vida biológica de los colombianos durante el siglo XX. En México, por ejemplo, en la primera mi- 
tad del siglo XX se mantuvo constante la estatura promedio y sólo empezó a mejorar después de 1950.

Mientras tanto, en muchos países de África no está mejorando la estatura. En algunos países incluso cae la estatura promedio. En Colombia el crecimiento de la estatura en promedio ha sido sostenida, e inclusive en todas las regiones y ciudades del país. Se ha encontrado convergencia, es decir, la dispersión entre las regiones y entre clases sociales se ha reducido.

El trabajo de Meisel y Acosta (2012) "estudia la evolución de la estatura de los colombianos nacidos entre 1946 y 1992. El análisis se realizó para los principales grupos étnicos del país. Utilizó una muestra con información antropométrica de 92.953 personas de la Encuesta Nacional de la Situación Nutricional en Colombia (ENSIN, 2010) publicada en 2011. Entre los principales resultados se encuentra que existe una diferencia significativa entre los grupos de clasificación étnica. Quienes se auto-reconocieron como afrodescendientes tienen estaturas promedio mayores al grupo de indígenas y mayores a quienes no se identifican con ninguno de estos dos grupos. Además, la brecha entre los afrocolombianos y los no étnicos es cada vez menor en el tiempo. El grupo de indígenas presenta un mayor potencial de crecimiento en el bienestar biológico y así ocurre cuando sus condiciones de vida mejoran."

\section{Estudios de Doctorado}

La influencia intelectual en el área monetaria, desde el pregrado, se fortaleció con estudios de especialización monetaria, cursos de Historia Económica, y la lectura a profundidad de la Historia Monetaria de Estados Unidos de Milton Friedman y Ana Schwartz (1971). Destaca que comúnmente se tiene la idea que Friedman, fue un aliado consejero económico de Augusto Pinochet, dictador de Chile, pero no lo reconocen como historiador económico con un profundo y riguroso análisis. Un gran libro, específicamente el capítulo sobre la Gran Depresión. Cuando investigó sobre la historia del Banco de la República, tuvo que leer y citar repetidas veces este libro.

La tesis de doctorado en economía le permitió graduarse en 1984 de la Universidad de Illinois. El tema desarrollado tuvo que ver con el boom cafetero de los años 1975 a 1979. Allí aplicó el modelo de enfermedad holandesa, formalizado por los economistas W. Corden y J. Neary (1982).

Luego, en Alemania fue alumno de Peter Neary economista irlandés experto en teoría del comercio internacional. Ellos formalizaron en un artículo de 1982, el modelo de enfermedad holandesa, que le parece sencillo y aplicable a los efectos del boom cafetero en la economía colombiana.

En la investigación ¿Por qué perdió la costa caribe el siglo XX?, aplicó el modelo de la enfermedad holandesa. Por tanto, sostiene que "los departamentos de la costa caribe constituyen las región más pobre del país. Se refleja en un ingreso per-cápita más bajo y en menores niveles de cobertura de servicios públicos entre otros indicadores económicos y sociales. Si se compara el PIB per cápita de 1995 de Sucre con el de Cundinamarca, departamento que 
ocupó el primer lugar en el país, la brecha se torna abismal".8 Tema que se relaciona con el desempeño y exportaciones de café, porque generó en Colombia una enfermedad holandesa y desplazó a todas las demás regiones no exportadoras de café, incluso todos los productos distintos del café y, en consecuencia, la Costa Caribe se vio afectada económicamente de una manera negativa.

En Illinois tomó un curso en el departamento de historia sobre Regímenes Esclavistas en América Latina. El profesor era Joseph Love, especialista en Brasil, y de quien después fue asistente de investigación. Love fue una gran influencia en su formación histórica en Illinois (Love, 2003). Ese profesor escribió un artículo sobre el pensamiento económico en América Latina en el siglo XX, en el cual analizó las ideas de Raúl Prebisch (1901-1986). Más tarde estudió al economista rumano Mihail Manoilescu (1891-1950), quien había defendido en la década de 1930 la tesis de la necesidad de que los países de Europa del Este se industrializaran pues había una tendencia al deterioro de los términos de intercambio entre la agricultura y la industria. Es decir, tenía ideas con alguna afinidad con las que luego desarrolló Raúl Prebisch.

El profesor Joseph Love le dijo a Meisel que si quería aprender algo de historia tenía que estudiar a Fernand Braudel (1902-1985), quien analiza los efectos de la economía y la geografía en la historia, porque era el mejor historiador del mundo en ese momento y tal vez de todo el siglo XX. Leyó casi todo lo que escribió Braudel y le tiene una enorme admiración. Piensa que a Braudel, como muchos clásicos, se le menciona mucho y se le estudia poco.

El libro de Braudel (2009) sobre la identidad de Francia tiene un prólogo maravilloso en donde habla sobre la campiña francesa desde la perspectiva de un soldado francés que en el momento de la derrota francesa durante la Segunda Guerra Mundial marcha con otros soldados hacia el exilio en Alemania a una prisión en Lubeck, en la cual estuvo detenido alrededor de cuatro años. Describe entonces la belleza de la campiña francesa, un contraste entre el drama humano de los que acaban de ser derrotados y marchan con incertidumbre al exilio en medio de la belleza inmensa del campo francés en primavera.

Es una descripción con fuerza literaria y desde el afecto por la tierra, un patriotismo de las cosas sencillas y cotidianas como la belleza del campo. Una declaración de una generación que le tocó vivir la guerra, la derrota y el destierro. Un drama que también vivió Raymond Aron en el exilio en Inglaterra y a quién le ofrecieron una plaza de profesor en Harvard, pero prefirió quedarse en Inglaterra dirigiendo un periódico de la Resistencia Francesa y representando a toda una generación golpeada y humillada por la derrota de su país.

Joseph Love había sido alumno en la Universidad de Columbia de Juan José Linz (19262013) sociólogo español, experto en teorías de los regímenes totalitarios y autoritarios en la transición a regímenes democráticos. Juan Linz era profesor de sociología política en la Universidad de Yale y fue profesor de varios sociólogos latinoamericanos y norteamericanos muy destacados, como Guillermo O'Donnell (1936-2011) quien desarrolló la tesis sobre el autoritarismo en un mundo burocrático, y Miguel Ángel Centeno, hoy profesor en Princeton.

Joseph Love puso en contacto a Meisel con Juan Linz, quién lo estimuló para hacer un doctorado en sociología en Yale. Allí llegó Meisel a mediados de 1984 y cursó una maestría (M. Phil.) y logró obtener candidatura al doctorado, pero nunca hizo la tesis.

8 Documentos de Trabajo sobre Economía Regional, 7. Cartagena: Banco de la República. 
En sociología en Yale fueron abundantes las lecturas de Raymond Aron, Max Weber, Isaiah Berlín, Karl Popper y Joseph A. Schumpeter. Asistió a un curso de Edward Said sobre los intelectuales en la literatura y profundizó en la obra de Albert Hirschman, uno de los economistas que más admira. Pero sobre todo estudió los artículos clásicos de Max Weber sobre la ciencia como vocación, la política como vocación, el carisma, las fuentes del poder y es un convencido de la enorme importancia intelectual de Max Weber.

A finales de 1986 decidió volver a Colombia, por razones personales (se separó de su primera esposa) y porque necesitaba empezar a trabajar para tener un mejor nivel de vida, ya que las restricciones económicas que implicaba su vida de estudiante eran grandes.

\section{Trabajo en el Banco de la República}

A comienzos de 1987 ingresa al Banco de la República a la Unidad de Investigaciones Económicas. Allí había un grupo de economistas de mucho talento, como Hernando José Gómez, Roberto Steiner, Sergio Clavijo, Pedro Nel Ospina, Israel Fainboim, Rodrigo Suescún, entre otros. Durante el primer año y medio trabajó en un proyecto de investigación sobre la historia del Banco de la República que ha sido elogiado, por ejemplo, por Carlos Marichal un notable investigador de la historia de la banca central e historiador financiero de América Latina. Marichal sostiene que esa es la mejor historia de un banco central en América Latina (Banco de la República, 1990).

En 1990 se trasladó a Barranquilla, pues quería volver a vivir en la Costa Caribe. Estuvo en Barranquilla entre 1990 y 1993 como Subgerente Técnico y luego Subgerente de Operación Bancaria en el Banco de la República. Allí contrajo matrimonio y nació su primera hija.

\section{Alemania}

En 1993, viajó a Kiel, Alemania para hacer una especialización en economía internacional en el Instituto de Economía Mundial. Allí se actualizó en los últimos avances de econometría y amplió sus conocimientos en comercio exterior. Estuvo en Kiel entre agosto de 1993 y junio de 1994. La biblioteca del Instituto es una de las mejores de Alemania. En su tiempo libre investigó sobre temas que sirvieran para historia económica y empresarial de la Costa Caribe. Allí recopiló material primario sobre Adolfo Held, SCADTA, la United Fruit Company, entre otros temas que luego analizó y escribió (Meisel y Viloria De La Hoz, 2003).

Adolfo Held fue uno de los fundadores del Banco Alemán Antioqueño, luego Banco Comercial Antioqueño, y vivía en Barranquilla como importador y exportador de tabaco con negocios de almacenes y ganadería. Introdujo el ganado cebú en Colombia; fue un hombre importante e influyente. Este material le sirvió para escribir el artículo citado y empezó a investigar en historia empresarial, un tema que no había explorado.

En Colombia había una idea generalizada de que los empresarios provenían casi exclusivamente de Antioquia, pero con las investigaciones realizadas en los últimos treinta años por autores como María Teresa Ripoll, lo que ha publicado Meisel y otros historiadores de la región costera, se cuenta con uno de los avances que han cambiado esa visión. 
Hay muy buen material primario para estudiar los empresarios costeños, como los archivos familiares de la familia Del Castillo, quienes donaron su archivo empresarial contable desde 1860 hasta 1960 al Banco de la República. Es un archivo muy completo y es uno de los mejores archivos empresariales de Colombia. Se encuentra en Cartagena en el Banco de la República. El archivo de la familia Pombo de Cartagena también pertenece ahora al Banco de la República.

En 1994 regresó a Colombia a la Dirección General del ICETEX en Bogotá, recién elegido el presidente Ernesto Samper y un amigo de la época de la universidad lo recomendó para este cargo. Desempeñó el cargo durante año y medio entre septiembre de 1994 y diciembre de 1995, y luego regresa al Banco de la República como investigador Senior de la Subgerencia de Estudios Económicos en Bogotá, porque se encontraba en licencia no remunerada del Banco.

Estuvo hasta enero de 1997, año en que regresa a Cartagena para ocupar la gerencia del Banco de la República, allí conforma un grupo de investigación en economía regional. Fue el primer grupo de investigación fuera de Bogotá que conformaba el Banco de la República. Le propuso a Miguel Urrutia contratar tres economistas jóvenes y recién graduados, para generar un proceso de formación a nivel regional junto con la creación y fortalecimiento de capacidades intelectuales y académicas.

\section{Grupos de investigación regionales}

En la actualidad el grupo de investigación Centro de Estudios sobre Economía Regional (CEER), del Banco de la República en Cartagena lo componen nueve profesionales y algunos se encuentran en Estados Unidos realizando estudios de doctorado. Cuatro de ellos ya hicieron doctorado, algunos son de la Costa, pero no todos. Ese grupo se ha consolidado y cuenta con la publicación de más de 250 documentos de trabajo, varios libros, y ha sido reconocido como grupo de investigación en economía regional, tanto en Colombia como a nivel internacional.

Es un esquema de investigación montado fuera de Bogotá, que se ha ampliado y ha tenido seguidores con un segundo grupo en Medellín sobre economía. Otro grupo se creó en Cali para el estudio de temas industriales. En Bucaramanga se estableció recientemente un grupo enfocado en temas ambientales y agropecuarios.

Meisel considera que su verdadera vocación es la de ser un investigador, y además, la consulta de los archivos es una pasión. Es uno de los historiadores económicos colombianos que más ha leído los archivos. Desde que tenía unos 21 años trabajó en el Archivo General de la Nación, uno de sus lugares predilectos. Ha investigado en el Archivo de Indias en Sevilla, donde estuvo durante tres meses en 1998. Fruto de esa pesquisa realizó un trabajo sobre las finanzas reales al final del periodo colonial en el virreinato de la Nueva Granada (Meisel, 2010). Igualmente, con esa información escribió un artículo sobre las finanzas de Cartagena durante el siglo XIX (Meisel, 2007).

En el Archivo General de la Nación ha investigado otros periodos, por ejemplo, el tema sobre la estatura. También sobre este tema estudió los archivos del Ministerio de Relaciones Exteriores, para construir una base de datos con los pasaportes en el periodo 1870-1910.

También ha trabajado en los Archivos del Atlántico, del Magdalena, de Cartagena, Valledupar y Mompox. Un día recibió una crítica de un joven historiador por no haber usado 
los archivos coloniales de Cartagena en un trabajo. Lo que no sabía ese poco informado historiador es que para efectos prácticos Cartagena no tiene archivos coloniales, debido a su historia traumática, el comején, la humedad y la desidia.

En 1987, trabajó en Estados Unidos, en el archivo de la Universidad de Princeton consultando el archivo personal de Edwin Kemmerer para el tema de la historia del Banco de la República. De ese trabajo de archivo también resultó el libro Edwin W. Kemmerer y el Banco de la República donde publicó una compilación de documentos inéditos sobre el trabajo de Kemmerer en Colombia (Meisel, López y Ruiz, 1994).

Otro archivo en el exterior donde ha investigado es el del Jardín Botánico de Madrid, donde hay material muy relevante para la historia de la Nueva Granada.

\section{Albert Hirschman (1915-2012) y las fronteras disciplinarias}

Hirschman es uno de los economistas que considera como una de sus influencias intelectuales, tiene un libro en donde destaca la transgresión de las fronteras disciplinarias (Hirschman, 1981). Siente una gran admiración por Hirschman, a quien tuvo oportunidad de conocer en Princeton cuando visitó el archivo de la Universidad en 1987.

Hirschman tuvo una formación clásica europea y humanística. Hizo su bachillerato en Berlín y como judío le tocó emigrar a Francia hacia 1933 en donde estudió economía. Vivió un tiempo en Italia y sabía francés, alemán, italiano, español e inglés. Luego emigró a Estados Unidos y se desempeñó como profesor. Estuvo en Colombia entre 1954 y 1958. También escribió un libro sobre política que se titula La pasión y los intereses (Hirschman, 1977). Afirmaba que no se debe ser respetuoso con las fronteras intelectuales porque son artificiales, la realidad es una y por razones prácticas burocráticas hemos impuesto una especialización en que tal tema es antropología, otra parcela es sociología, la siguiente es economía, la otra es historia y aquella es psicología. En fin, el conocimiento es uno solo y el hombre es uno solo y todo sirve para entender los procesos históricos que son complejos.

En Albert Hirschman destaca que "es un pensador dispuesto a traspasar las barreras disciplinarias, sus aportes tuvieron en cuenta aspectos económicos, políticos, antropológicos e históricos. Por esta razón, las discusiones sobre el problema de los rezagos regionales se dividen según las disciplinas mencionadas. Se presentan conclusiones de los desequilibrios económicos regionales mostrando que la ventaja comparativa radica en haber analizado el tema en sus múltiples dimensiones y no solamente desde la teoría económica" (Meisel, 2008).

Considera fundamental que un investigador construya unos derroteros o patrones constantes que le interesan, por ejemplo, a Meisel el tema sobre la Costa le ha interesado, porque es una región sobre la cual se sabía muy poco y además, siente que es una región que ha sido discriminada, ha estado rezagada, y es víctima de muchos estereotipos, así como del centralismo. 


\section{Obra de Adolfo Meisel Roca}

(1980) Esclavitud, mestizaje y haciendas en la provincia de Cartagena, 1533-1851. Desarrollo y Sociedad, 4, julio. CEDE. Bogotá: Uniandes.

(1987) Antecedentes históricos de la banca central en Colombia: el patrón metálico 1821-1880. Bogotá: Banco de la República.

(1989) Historia del Banco de la República. Bogotá: Banco de la República.

(1990) El Banco de la República: antecedentes, evolución y estructura. Autores varios. Bogotá: Banco de la República.

(1994) Kemmerer y el Banco de la República: Diarios y Documentos. A. Meisel Roca, A. López, F. Ruiz (comps). Bogotá: Banco de la República.

(1999) ¿Por qué perdió la Costa Caribe el siglo XX? Documentos de Trabajo sobre Economía Regional, 7, Cartagena: Banco de la República.

(1999) Los alemanes en el caribe colombiano: El caso de Adolfo Held, 1880-1927. Coautor: Joaquín Viloria. Cuadernos de Historia Económica y Empresarial, 1. Cartagena: Banco de la República.

(2003) Barranquilla Hanseática: el caso de un empresario alemán. Coautor: Joaquín Viloria De La Hoz. En Carlos Dávila L. De Guevara (comp.), Empresas y empresarios en la Historia de Colombia. Siglos XIX-XX, tomo I. Grupo Editorial Norma, Uniandes, CEPAL.

(2004) Entre Cádiz y Cartagena de Indias: la red familiar de los Amador, del comercio a la lucha por la independencia americana. Cuadernos de Historia Económica y Empresarial, 12, julio. Cartagena: Banco de la República.

(2004) La estatura de los colombianos: un ensayo de antropometría histórica, 1910-2002. Coautora: Margarita Vega. Documentos de Trabajo sobre Economía Regional, 45, mayo. Cartagena: Banco de la República.

(2007) La crisis fiscal de Cartagena en la era de la independencia, 1808-1821. Centro de Investigaciones del Caribe Colombiano. Cartagena: Banco de la República.

(2008) Albert Hirschman y los desequilibrios económicos regionales: de la economía a la política, pasando por la antropología y la historia. Desarrollo y Sociedad, 62, 203-223.

(2010) Crecimiento, mestizaje y presión fiscal en el virreinato de la Nueva Granada, 1761-1800. CEER. Cartagena: Banco de la República.

(2012) Diferencias étnicas en Colombia: una mirada antropométrica. Coautora: Karina Acosta. Documentos de Trabajo sobre Economía Regional, 166, abril. Cartagena: Banco de la República.

(2016) Memorias de hacienda y del tesoro de la Nueva Granada y Colombia. Coautora: María Teresa Ramírez. Siglo XIX Editores. 


\section{Referencias}

Bohorquez, L. A. (1956). La evolución educativa en Colombia. Bogotá: Publicaciones Cultural Colombiana.

Braudel, F. (2009). La identidad de Francia. El espacio y la historia. Barcelona: Gedisa.

Corden, W. M. y Neary, J. P. (1982). Booming sector and De-industrialization in a small open economy. The Economic Journal, 92(368), 825-848.

El Heraldo. (2017). Un recorrido por la historia de El Prado. Recuperado de http:// www.elheraldo.co/entretenimiento/un-recorrido-por-la-historia-de-el-prado-412463

Elías, N. (1994). El proceso de la civilización: Investigaciones sociogenéticas y psicogenéticas. México DF: Fondo de Cultura Económica.

Elías, N. y Dunning. E. (2016). Deporte y ocio en el proceso de la civilización. México DC: Fondo de Cultura Económica.

Fogel, R. (1960). The Union Pacific Railroad: A case in premature enterprise. Baltimore, MD: Johns Hopkins University Press

Fogel, R. (1964). Railroads and American economic growth: Essays in econometric history. Baltimore, MD: Johns Hopkins University.

Fogel, R. (1989). Without consent or contract: The rise and fall of American Slavery. Nueva York: Norton.

Fogel, R. W. y Engerman, S. (1974). Time on the cross: The economics of American Slavery. Trad. Tiempo en la cruz: La economía esclavista en los Estados Unidos. Siglo XXI de España, 1981.

Friedman, M. y Schwartz, A. J. (1971). Historia monetaria de los Estados Unidos 1867-1960. Princeton, NJ: Princeton University Press.

Harnecker, M. (2007). Los Conceptos elementales del Materialismo Histórico. México DF: Siglo XXI Editores.

Hirschman, A. (1977). The passions and the interests. Princeton, NJ. Princeton University Press.

Hirschman, A. (1981). Essays in trespassing, economics to politics and beyond. Cambridge, NY: Cambridge University Press.

Jaramillo Uribe, J. (1964). El pensamiento colombiano en el siglo XIX. Bogotá: Editorial Temis.

Linz, J. J. (2000). Totalitarian and Authoritarian Regimes. Boulder, CO: Lynne Rienner Publishers.

Linz, J. J. y Stepan, A. (1978). The breakdown of democratic regimes. Johns Hopkins University Press.

Love, J. (2003). Acotaciones a la influencia de las ideas económicas de Mihail Manoilescu en Portugal y España. Empresas Políticas, 2(3), 101-105.

Love, J. (2011). Ideias e ideologias económicas na América Latina. Historia da América Latina, $8,161-242 ; 679-685$. 
Manoilescu, M. (1931). The theory of protection and international trade. Londres: P.S. King and Son.

Muller de Ceballos, I. (s.f.). La primera organización de un Sistema de Escuelas Normales en Colombia. Ubicación del Decreto Orgánico de Instrucción Pública Primaria de 1870, en una perspectiva internacional. Recuperado de: www.pedagogica.edu.co/storage/rce/articulos/20_05ens.pdf

Weiler, V. (2016). Repensar a Norbert Elias en clave de futuro. Bogotá: Universidad Nacional de Colombia. 